\title{
Abandonment of Patients in Emergency Department of Tertiary Care Hospital of Eastern Nepal- an Observational Study
}

RITESH CHAUDHARY ( $\square$ ritesh948@yahoo.com )

BP Koirala Institute of Health Sciences https://orcid.org/0000-0001-6450-7845

\section{Rabin Bhandari}

BP Koirala Institute of Health Sciences

Saroj Giri

BP Koirala Institute of Health Sciences

Vijay Shrivastav

BP Koirala Institute of Health Sciences

Rupak Bhandari

BP Koirala Institute of Health Sciences

\section{Research}

Keywords: abandonment of patients, emergency department, Nepal

Posted Date: November 9th, 2021

DOI: https://doi.org/10.21203/rs.3.rs-1031308/v1

License: (c) (1) This work is licensed under a Creative Commons Attribution 4.0 International License. Read Full License 


\section{Abstract \\ Background}

Patient abandonment in the emergency department has been reported in various parts of the world although the implications and social circumstances may vary in context to its definition. The current study intends to review the characteristics of twenty-four (24) abandoned patients in the emergency department of tertiary care hospital of Eastern Nepal.

\section{Methods}

This was a prospective observational study conducted among all abandoned patients presenting to tertiary care hospital in eastern Nepal from July 2018 to July 2020.

\section{Results}

Twenty four (24) patients were enrolled in the study. 22 (91.7\%) were male and 2 (8.3\%) were female with a mean age of $43.2 \pm 14.4$ SD. The median length of stay (LOS) was $72(Q 1, Q 3,23.5,960)$ hours in the emergency department. Seven, 7 (43.75\%) cases of mortality were due to medical illness, 4 (25\%) cases of mortality were due to surgical illness and $5(31.25 \%)$ cases of mortality were with undifferentiated presentations $(p=0.012) .15$ of $24(62.5 \%)$ patients over 40 years of age experienced a longer LOS $(p=$ $0.34)$ and $(75 \%) 12$ of 16 have a higher mortality than younger patients $(p=0.30)$. More than (USD) $\$ 50$ was invested in an abandoned case that was taken care of by NGOs. $6(25 \%)$ of abandoned patients were taken care of by other centers like NGOs and welfare centers.

\section{Conclusions}

Abandoned patients in the middle-aged adults with medical comorbidity experienced longer hospital stays and as an indicator of mortality. Financial disparities were observed among abandoned patients taken care of by charitable organizations and tertiary care hospital.

\section{Background}

Patient abandonment in emergency department (ED) has been reported in various parts of the world although the implications and social circumstances may vary in context to its definition.

Various terms like "granny dumping," or "packed- suitcase-syndrome" have been used to describe the "patient abandonment" in different scenarios, resulted detrimental outcome [1, 2]. The situation has been reported from Nepal, across the United States of America (USA), Trinidad and Tobago and India. We have used the term patient abandonment to refer to patients brought without their identity by social workers, 
police or community people and are left abandoned in the doorstep of ED. Patient abandonment not only causes overcrowding at government hospitals but at the same time others serious patients cannot obtain the care they need. Such burden seems undesirable for hospital based growing social issue regarding abandoned patients due to loss of revenue and ill will. It is a multidimensional problem, in conflict of the concept towards achievement of Millennium Development Goals (MDGs) and poses a great challenge to social security [3-7].

The current study intends to review the characteristics of twenty- four (24) abandoned patients in emergency department of tertiary care hospital of Eastern Nepal.

\section{Methods}

\section{Study type}

A prospective observational study was conducted in emergency department of a BPKIHS in eastern Nepal from July 2018 to July 2020.

\section{Setting}

The study was carried out in emergency ward of a tertiary hospital in eastern Nepal. It is 800 - bedded tertiary hospital with 85 beds in emergency ward, with specified areas i.e. area A with 4 beds, area B with 4 beds, area $\mathrm{C} 1$ and $\mathrm{C} 2$ with 50 beds, area $\mathrm{D}$ with 5 beds and area $\mathrm{E}$ with 22 beds respectively and average rate of approximately 100 patients per day. Emergency ward care is provided 24 hours a day, serving more than 40,000 patients a year.

\section{Participants}

All the patients of who were left abandoned in emergency department of BPKIHS were included in the study. Due to legal obligation, consent was provided from police or non-governmental organizations (NGOs) and welfare centres who later claim as a care taker.

\section{Sample size calculation}

The calculated sample size was 25 based on the previous year census 2018 from medical record section, BPKIHS. It was found that approximately 25 cases were recorded as abandoned in emergency ward.

\section{Sampling techniques}

The study was conducted after the patient is left abandoned in the emergency ward of BPKIHS. Information regarding abandonment of patient was collected after triaging patient where the patient had been named as "Unknown/ Unclaimed/ Heirless Case" or as " “Q patients left abandoned in the emergency ward of BPKIHS were assessed by using code instead of name to maintain their confidentiality. Information regarding age, gender, address and care taker where possible were gathered from the patient or police as feasible. A convenient sampling method was used by using 
non-probability sampling i.e. purposive sampling methods. All the cases were included during the period from July 2018 to July 2020 .

\section{Outcomes}

Patient's clinical details like AVPU ((alert, verbally responsive, painfully responsive and unresponsive) scale, length of hospital stay (LOS), death, transferred to ward or referred and discharged from the hospital were the outcome variables to be applied in the study.

\section{Statistical analysis}

The data obtained were entered in a Microsoft excel spread sheet and analyzed. Statistical Package for the Social Sciences (SPSS) version 11.5 was used to carry out the descriptive and inferential statistics. Percentage, mean, standard deviation (SD), median, was calculated along with graphical and tabular presentation. The $\chi 2$ test was applied to compare differences in the results of quantitative variables.

\section{Results}

During the study period, five (5) abandoned patients were found in year 2018, 15 abandoned patients in year 2019 and 4 abandoned patients in year 2019 in ED of BPKIHS. Twenty four (24) abandoned patients were enrolled in the study. The mean age of the patient was $43.2 \pm 14.4$ SD with male female ratio of 11:1. Approximately, 42\% (10) cases were able to be located from hilly region, 5 cases from Terai region, 2 cases from neighbouring country India and in 7 cases were not able to locate their regions i.e. from unknown region. 8 cases admitted in ED during morning shift (8am - 2pm), 9 cases during evening shifts (2pm - 8pm) and 7 cases were admitted during night shifts (8pm - 8am). 41.7\% (10) cases were diagnosed having medical comorbidities such as: stroke, chronic liver disease, community acquired pneumonia, acute coronary syndrome and sepsis, 33.3\% (8) cases were having surgical comorbidities such as pancreatitis, necrotizing fasciitis, psoas abscess, osteomyelitis, intracranial haemorrhage, and dislocation of hip joint while $20.8 \%$ (5) cases were diagnosed as undifferentiated presentations. 1 case was diagnosed as psychiatry related. The median length of stay (LOS) of abandoned patients was 72 (Q1, Q3, 23.5, 960) hours as shown in (Table 1). 
Characteristics of abandoned patients $(n=24)$.

\begin{tabular}{|ll|}
\hline Patients status & Description \\
\hline Year of admission: & $5(20.8 \%)$ \\
2018 & $15(62.5 \%)$ \\
2020 & $4(16.7 \%)$ \\
\hline Male & \\
Female & $22(91.7 \%)$ \\
Age (years) & $2(8.3 \%$ \\
$15-39$ & $43.2 \pm 14.4$ \\
$40-59$ & $9(37.5 \%)$ \\
$\geq 60$ & $10(41.7 \%)$ \\
Address: & $5(20.8 \%)$ \\
Hilly region & $10(41.7 \%)$ \\
Terai region & $5(20.8 \%)$ \\
Unknown region & $7(29.2 \%)$ \\
Outside Nepal & $2(8.3 \%)$ \\
\hline Australasian Triage Scale (ATS): & $8(33.3 \%)$ \\
\hline (Immediate life threatening) & $9(37.5 \%)$ \\
\hline Time of admission: & $7(29.2 \%)$ \\
Morning shift (8am - 2pm) & $3(12.5 \%)$ \\
Evening shift (2pm - 8pm) & $11(45.8 \%)$ \\
\hline ight shift (8pm - 8am) & $10(41.7 \%)$ \\
\hline
\end{tabular}

In the study, three (3) patients stayed in ED for less than 24 hours who were triaged as Australasian Triage Scale (ATS)-1. Six (6) patients stayed in ED for at least 7 days who were triaged ATS-2. Four (4) patients stayed in ED for more than 30 days who were triaged ATS-3 $(p=0.07)$ (Table 2). 


\section{Patients status}

Diagnosis:

Medical related

Surgical related

Psychiatric related

Undifferentiated Presentation
Description

$10(41.7 \%)$

$8(33.3 \%)$

$1(4.2 \%)$

$5(20.8 \%)$

$72(\mathrm{Q} 1, \mathrm{Q} 3,23.5,960)$

In the study, three (3) patients stayed in ED for less than 24 hours who were triaged as Australasian Triage Scale (ATS)-1. Six (6) patients stayed in ED for at least 7 days who were triaged ATS-2. Four (4) patients stayed in ED for more than 30 days who were triaged ATS-3 $(p=0.07)$ (Table 2).

$66 \%$ (16) cases died during the hospital stay. Seven, 7 (43.75\%) cases of mortality were due to medical comorbidities. $25 \%$ (4) cases of mortality were due to surgical comorbidities and 5 (31.25\%) cases of mortality were with undifferentiated presentations $(p=0.012)$.

The study found that abandoned patients who were mental status of (AVPU) scale of Alert, $(A ; n=4)$ expired in ED. In contrast, those who were (AVPU) scale of painfully responsive $(P ; n=5)$ were discharged from ED ( $p=0.07)$. Twelve, 12 of $24(50 \%)$ patients over 40 years of age experienced a longer LOS in the Emergency Department $(p=0.34)$, and have a higher mortality than younger patients, $(75 \%) 12$ of $16(p=$ 0.30) (Table 2).

Eighteen (18) abandoned patients were under care of staffs and healthcare workers including consultants, residents, medical officers, interns, nurses, health attendants and nursing in-charge of emergency department. 25\% (6) of abandoned patients were taken care by other centres like NGOs and welfare centres. More than United States Dollar (USD) \$50 corresponding to Nepalese rupees (NRs) 5000 was invested in an abandoned case who was taken care by NGOs. 
Table 2

Outcome of abandoned patients ( $n=24)$.

\begin{tabular}{|c|c|c|c|c|}
\hline Length of hospital stay (LOS) & Expired & LAMA & Discharge & $P$ value \\
\hline$\leq 24$ hours & 4 & 1 & 1 & 0.86 \\
\hline$\leq 7$ days & 7 & 1 & 4 & \\
\hline$\leq 14$ days & 2 & & 0 & \\
\hline$\leq 30$ days & 2 & & 0 & \\
\hline$\geq 30$ days & 1 & & 1 & \\
\hline Age (years) & Expired & LAMA & Discharge & $P$ value \\
\hline $15-39$ & 4 & 2 & 3 & 0.30 \\
\hline 40- 59 & 8 & & 2 & \\
\hline$\geq 60$ & 4 & & 1 & \\
\hline Mental status (AVPU) & Expired & LAMA & Discharge & $P$ value \\
\hline Alert & 4 & 1 & 1 & 0.01 \\
\hline Verbal & 7 & 1 & 5 & \\
\hline Pain & 5 & & & \\
\hline \multicolumn{5}{|l|}{ Unconscious } \\
\hline LOS with age groups (years) & $15-39$ & $40-59$ & $\geq 60$ & P value \\
\hline$\leq 24$ hours & 2 & 4 & 3 & 0.34 \\
\hline$\leq 7$ days & 4 & 5 & 1 & \\
\hline$\leq 14$ days & 2 & 1 & 1 & \\
\hline$\leq 30$ days & 1 & & & \\
\hline \multicolumn{5}{|l|}{$\geq 30$ days } \\
\hline LOS & ATS-1 & ATS-2 & ATS-3 & $P$ value \\
\hline$\leq 24$ hours & 3 & 3 & 0 & 0.07 \\
\hline$\leq 7$ days & 0 & 6 & 6 & \\
\hline$\leq 14$ days & 0 & 1 & 1 & \\
\hline$\leq 30$ days & 0 & 0 & 2 & \\
\hline$\geq 30$ days & 0 & 1 & 1 & \\
\hline Diagnosis: & Expired & LAMA & Discharge & $P$ value \\
\hline
\end{tabular}




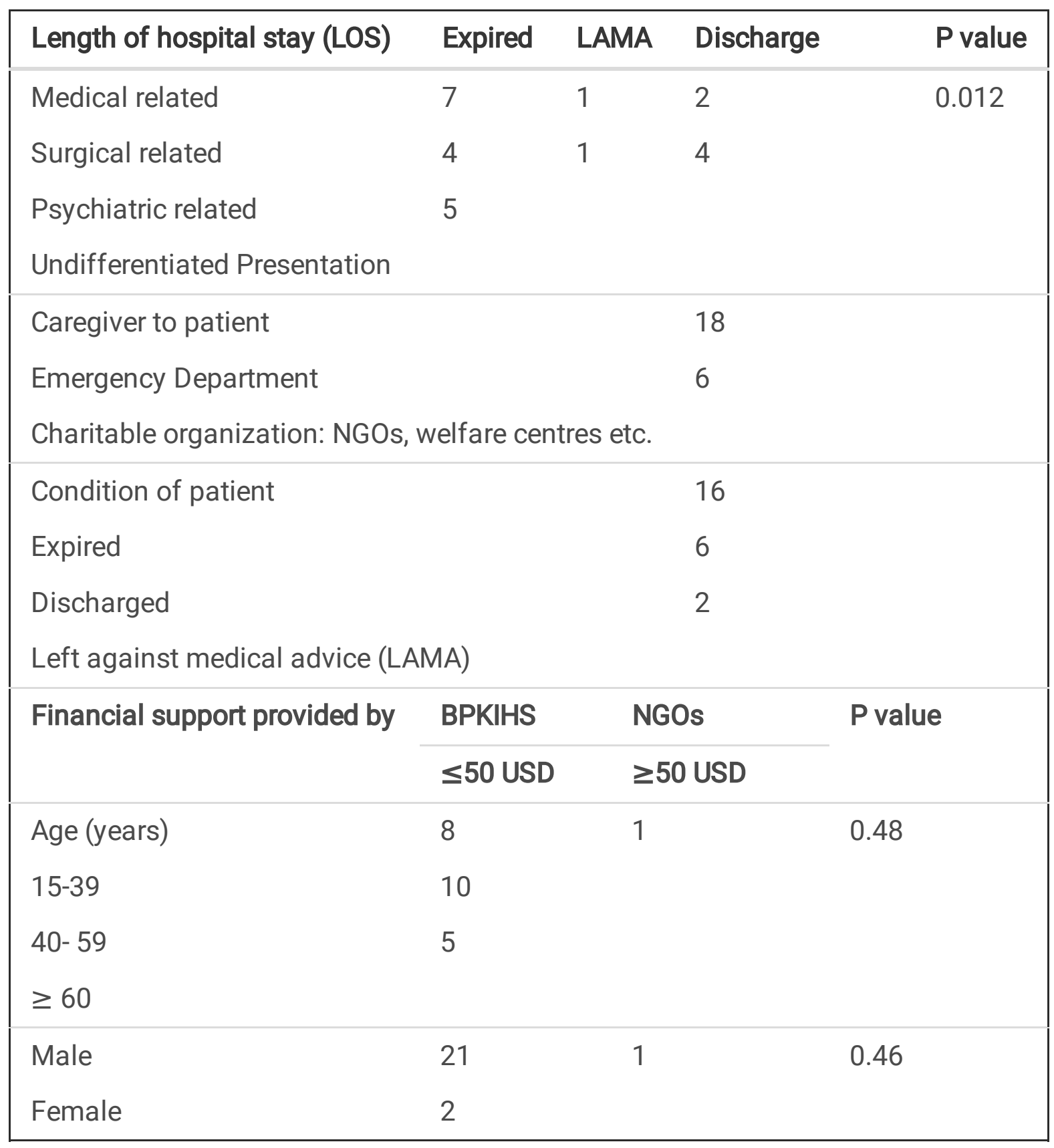

\section{Discussion}

Patient abandonment is a burden on patient's perspective as well as hospital itself at a point of time. Since others non-abandoned patients may not obtain the same optimum care that they need resulting access block and increase ED overcrowding [8].

The study have reported that majority of adult patients aged 40 to 59 years with medical illness showed longer length of hospital stay and were the primary cause of death in ED [9]. The study reported from Bir hospital of Nepal had already started allocating beds for abandoned patients who were left in the ED for longer period of time. At the same time the hospital had been providing a free medical service to the abandoned, helpless and poor patients [10]. 
The AVPU scale which is a simplified 4-part (alert, verbally responsive, painfully responsive and unresponsive) scale and is well described the level of patient's consciousness was expected to be associated with patient's outcome [11]. Surprisingly, $80 \%$ of the patient expired who were alert (A) expired and $71.4 \%$ were discharged who were responsive to $(P)$ painful stimuli (Table 2$)$. This was possible by the staffs of ED organising plan and management strategies by themselves to take care of these patients until their disposition.

Unlikely study done in western countries, the current study did not observe any investment for the poor who have been left behind, struggling daily to acquire food, shelter, healthcare, and other necessities of life [12]. In the study more than $\$ 200$ has been seen invested who are taken care by charitable organizations hospital whereas, less than USD fifty (\$50) was invested by BPKIHS to abandoned patients. These disparities could be because of underdevelopment of infrastructure and its legislative initiatives of hospital. In March 2013, the government of Nepal had expanded its program and has allocated about $7 \%$ (percent) of its budget to the Ministry of Health and Population that offers free medical care to such patients [13]. According to National Population and Housing Census 2011 and The World Bank 2019, Nepal has an estimated population of about 26.5 million people, and about $39 \%$ (percent) of the population live in poverty $[14,15]$. Due to unaffordable cost of medical care for longer period of time most of the families are bound for abandoning their patient at emergency doorsteps.

Whatever the circumstances, the treating physicians feel that they have no choice but to keep this patient until a further plan can be made or their family member can be traced. One study reported from India that apart from treatment of an abandoned patient, the doctors' efforts were successful to trace their family member [16].

Our study has a few limitations. The sample was small and single centred. More researches needed to find out the factors associated with abandonment of patients in tertiary hospitals of Nepal. Both local and central government of Nepal should launch a separate budget program for services provided to uninsured, low-income and abandoned patients (uncompensated care costs) that include all types of medical payments annually for the better health care system. The efforts of healthcare workers of emergency department as well as inter-department consultants are appreciative for going above and beyond their duties and even at their best going out their way to help these abandoned cases in all Emergency Department of tertiary care centre of Nepal.

\section{Conclusions}

Abandoned patients in middle- aged adult with medical comorbidity experienced a longer hospital stays and as an indicator of mortality. Financial disparities among abandoned patients under care taken by charitable organizations and tertiary care hospital can also be addressed by concerned authorities inside the medical institution for development of infrastructure of hospital and its legislative initiatives towards the end point of care. 


\section{Abbreviations}

AVPU: $\quad$ Alert, verbally responsive, painfully responsive and unresponsive

ATS: $\quad$ Australasian Triage Scale

BPKIHS; B.P Koirala Institute of Health Sciences

ED: $\quad$ Emergency Department

LOS: $\quad$ Length of Stay

MDGs: Millennium Development Goals

NGOs: $\quad$ Non-Government Organisations

SD: $\quad$ Standard Deviation

SPSS: $\quad$ Statistical Package for the Social Sciences

USD: $\quad$ United States Dollar

\section{Declarations}

Ethical approval and consent to participate: Approved from Institutional Review Board with reference number of 204-076-077- IRC. Due to legal obligation, an informed consent was provided from police or NGOs) or welfare centres who later claim as a care taker.

Consent for publication: Not applicable

Availability of data and materials: The dataset analysed during the current study is available from the corresponding author on reasonable request.

Competing interests: The authors declare that they have no competing interests.

Funding: None.

Authors' contributions: RC made substantial contributions to the study conception and design and interpretation of results; the drafting and revision of the manuscript; and gave approval to the final version. RB made substantial contributions to the interpretation of results; the drafting and revision of the manuscript; and gave approval to the final version. SG, VS, RB made substantial contributions to revision of the manuscript; and gave approval to the final version. All authors read and approved the final manuscript. 
Acknowledgements: The authors would like to thank all the staffs and healthcare workers including consultants, residents, medical officers, interns, nurses, health attendants and nursing in-charge of emergency department for taking care of abandoned patients.

Authors' information: B.P Koirala Institute of Health Sciences. Dharan, Nepal.

\section{References}

1. Conard JR, Granny Dumping: Granny dumping: The hospital's duty of care to patients who have nowhere to go. Yale \& Policy Review. 1992; 10(2): 14. [Full Text]

2. Geers JM, Pasupathy KS, Lovik KK, et al.Characterization of emergency department abandonment using a real-time location system. Am J Emerg Med. 2020; 38(4): 759-762. [PubMed I DOI: 10.1016/j.ajem.2019.06.025]

3. Chaudhary R, Bhandari R, Jirel S, Shrivastav V, Bhandari R. Abandonment of Patient in Emergency Department of Tertiary Care Hospital of Eastern Nepal - a Case Study. Journal of BP Koirala Institute of Health Sciences. 2020; 3(1): 135-137. [Full Text]

4. Culbertson J. Some elderly and handicapped being abandoned at hospitals. The New York Times [newspaper online] 1981 Nov 1. Details are given at https://www.nytimes.com/1981/11/01/nyregion/someelderly-and handicapped-being-abandonedat-hospitals.html. [Full Text]

5. Kalifa Clyne. Elderly abandoned at hospitals | The Trinidad Guardian Newspaper. [newspaper online] 2016 Nov 12. Details are given at http://www.guardian.co.tt/news/2016-11-12/elderly-abandonedhospitals. [Full Text]

6. Emergency rooms bearing burden of abandoned elderly. Deseret News [newspaper online] 1991 Nov 29. Details are given at https://www.deseret.com/1991/11/29/18954194/emergency-rooms-bearingburden-of-abandoned-elderly. [Full Text]

7. India's forgotten and abandoned patients. BBC NEWS, South Asia [newspaper online] 2009 Aug 13. Details are given at http://news.bbc.co.uk/2/hi/south_asia/8197498.stm.

8. Fatovich DM, Nagree Y, Sprivulis P. Access block causes emergency department overcrowding and ambulance diversion in Perth, Western Australia. Emerg Med J. 2005; 22(5):351-354. [Pub Med]. doi:10.1136/emj.2004.018002.

9. Chong CP, Haywood C, Barker A, Lim WK. Is Emergency Department length of stay associated with inpatient mortality? Australas J Ageing. 2013; 32(2):122-124. doi:10.1111/j.17416612.2012.00651.x.

10. Abandoned patients face neglect in Bir hospital. The Himalayan Times [newspaper online]. 2017 July 01. Details are given at https://thehimalayantimes.com/kathmandu/abandoned-patients-faceneglect-bir-hospital. [Full Text]

11. Simon B, Nobay F. Altered mental status. In: Mahadevan SV, Garmel GM, editors. An Introduction to Clinical Emergency Medicine. 2nd ed. Cambridge: Cambridge University Press; 2012. p. 185-96. 
12. Elrod J.K, Fortenberry J.L. Advancing indigent healthcare services through adaptive reuse: repurposing abandoned buildings as medical clinics for disadvantaged populations. BMC Health Serv Res. 2017; 17(Suppl 4); 805. [DOI: https://doi.org/10.1186/s12913-017-2752-8]

13. Usha KC. Medical Costs Force Nepal's Poor to Abandon Family Members. 2013 April 2. Details are given at https://globalpressjournal.com/asia/nepal/medical-costs-force-nepal-s-poor-to-abandonfamily-members. [Full Text]

14. NPHC. Nepal National Population and Housing Census. 2011;01. Details are given at https://unstats.un.org/unsd/demographic-social/census/documents/Nepal/Nepal-Census-2011Vol1. [Full Text]

15. The World Bank in Nepal. 2020 Apr 12. Details are given at https://www.worldbank.org/en/country/nepal/overview. [Full Text]

16. Shuja-ul-Haq. In Srinagar, a psychiatric hospital looks for abandoned patients' homes. India Today [newspaper online].2016 May 06. Details are given at https://www.indiatoday.in > India. [Full Text] 